\title{
EL ANÁLISIS DEL DISCURSO \\ DESDE LA PERSPECTIVA FOUCAULDIANA: MÉTODO Y GENERACIÓN DEL CONOCIMIENTO
}

Carlos González-Domínguez Lenin Martell-Gámez

\section{Resumen}

Las ciencias sociales, en su necesidad de recurrir a diferentes marcos teóricos y metodológicos, encuentran en el análisis del discurso una valiosa herramienta. Sin embargo, la recurrencia al análisis del discurso no es predominante, y quienes lo utilizan suelen ser analistas de ciertas disciplinas como la comunicación, la retórica o el resto de las ciencias del lenguaje. Los otros científicos sociales cuando practican el análisis del discurso suelen confundirlo, inconscientemente, como si se tratase de una hermenéutica; o bien, porque lo desconocen por completo, está fuera de sus recursos analíticos. Por esto, interesa en este artículo reflexionar la importancia y posibilidades epistemológicas y heurísticas del análisis del discurso, como elemento teóricometodológico en el desarrollo de las ciencias sociales.

Palabras clave: análisis del discurso, sujeto, arqueología y genealogía foucauldiana.

\section{Abstract}

Social Sciences finds in the discourse analysis a valuable tool, when it fosters its knowledge in different theoretical and methodological frames. However, turning to the discourse analysis is not predominant in this field. Scholars, who utilize it, are usually academicians who stem from certain disciplines such 
as Communication and Rhetoric Studies, or Language Sciences. Other social scientists, when intending to put the discourse analysis into practice, either they ignore it, confuse it, or they do not have the analytical resources to approach it. This is why our main interest in this paper aims at reflecting about the discourse analysis importance and its epistemological possibilities-especially, as a theoretical-methodological element of the Social Science development.

Keywords: discourse analysis, subject, foucauldian archeology and genealogy.

\section{INTRODUCCIÓN}

Aparecido recientemente en la historia de las ciencias sociales, el análisis del discurso se presenta en muchos trabajos científicos apenas como un recurso metodológico que no alcanza a explotar lo que Michel Foucault llama la genealogía del saber y del poder. En otras palabras, el análisis del discurso suele ser simplemente un recurso metodológico para dar cuenta de la discursividad de los corpus analizados que, incluso, no serían resultado estrictamente del análisis del discurso, sino del análisis de contenido.

En estas circunstancias, interesa entonces poner de relieve la profundidad no sólo analítica (sobre un plano puramente metodológico), sino sobre todo su potencial epistemológico, en la generación del conocimiento de lo social. Esto significa que el investigador que recurre al análisis del discurso tiene en sus manos una herramienta capaz de trabajar como un arqueólogo' , encontrando las reglas de formación y de las exclusiones de los discursos, así como las genealogías, las filiaciones discursivas, y con esto aprehender causas y consecuencias que permiten comprender e interpretar los objetos de estudio, en el proceso de continuidad y discontinuidad histórica (Foucault, 1990). Atravesar las anteriores dimensiones significa reconocer los trayectos político, económico, cultural e incluso científico de los objetos de estudio. Pero además, trabajar con el análisis del discurso implica una mirada crítica que, por definición, ha de proponer, al interior del saber producido, una transformación y/o una nueva percepción de la realidad.

Dicho lo anterior, no se tratará aquí de realizar una apología del análisis del discurso, como panacea teórica-metodológica en las ciencias sociales, sino de revisar algunos aspectos relevantes que implica su utilización, para reconocer su heurística en la producción del saber y del poder de la ciencia, frente al devenir de las sociedades.

Así, en las próximas líneas, siguiendo la perspectiva foucauldiana, revisaremos las conexiones del análisis del discurso con el proceso de investigación, con la epistemología y con el plano histórico y hermenéutico, con los cuales forma una trama inexorable. Con lo anterior, esperamos mostrar cómo es necesario ampliar la utilización de este método en las prácticas científico-analíticas en las ciencias sociales.

\section{EL ANÁLISIS DEL DISCURSO COMO ARQUEOLOGÍA DEL SABER Y COMO PRÁCTICA: UN MÉTODO}

Entre los telones epistemológico, teórico y metodológico está el método. Hoy, a todas luces, el análisis del discurso no debe concebirse como un referente teórico ni metodológico; es sobre todo un método. Si partimos de una de las obras fundadoras del análisis del discurso, La arqueología del saber de Michel Foucault (1990), nos queda claro que el filósofo francés no desarrolla un tratado metodológico, su preocupación es eminentemente de carácter filosófico, epistemológico y teórico. Es lógicamente comprensible que, en el contexto de la aparición de esta obra de Foucault, era necesario primeramente sentar las bases de lo que, posteriormente, sería el análisis del discurso; luego se ha tenido que abordar el plano metodológico que, en todo caso, corresponde desarrollarlo a cada analista, por estar condicionado a su objeto de estudio. Lo que Foucault refiere a lo largo de su obra es el menester de producir rupturas epistemológicas (inspirado en la obra de Gaston Bachelard), para pensar, vivir y percibir la realidad bajo el paradigma de la discontinuidad ${ }^{2}$. Este trabajo de ruptura epistemológica no es otra cosa que la arqueología y la genealogía de los discursos. En consecuencia, los discursos, analizados en su contexto histórico, nos permiten apreciar el lugar que ocupa el hombre como sujeto de lenguaje, de trabajo y de vida (Foucault, 1966: 355-364).

Bajo las anteriores consideraciones, nos encontramos frente a la

Por razones de espacio no vamos a desarrollar la importancia del paradigma de la discontinuidad. Basta señalar que este concepto se refiere a la posibilidad de emergencia, suspensión o rehabilitación de los 
problemática del discurso científico mismo, en lo que representa como saber y como práctica. Foucault demuestra, como todos sabemos, la emergencia de los discursos psiquiátricos, médicos, jurídicos, durante los siglos XVII, XVIII y XIX que en su "voluntad de saber" terminan por una voluntad de poder tácito que es una práctica política sobre el sujeto. De aquí que en todo discurso (incluyendo el científico) se presupone una acción. En 1970, en la ceremonia de su integración al Collège de France, Foucault lo dice en estas palabras ya clásicas:

"Lo que es el discurso en su realidad material de cosa pronunciada o escrita: [la] inquietud en relación a esta existencia transitiva destinada a borrarse sin duda, pero en una duración que no nos pertenece; inquietud a sentir bajo esta actividad, sin embargo cotidiana y gris, los poderes y los peligros que imaginamos mal; inquietud a sospechar de las luchas, de las victorias, de los golpes, de la dominación, de la servidumbre, a través de tantas palabras cuyo uso, desde hace tiempo, ha reducido las asperezas. Pero, ¿qué hay de tan peligroso en el hecho de que la gente hable, y que sus discursos proliferen indefinidamente? ¿Dónde está el peligro? He aquí la hipótesis que propongo: para fijar el lugar -o quizá el teatro provisional- del trabajo que realizo: supongo que en toda sociedad la producción del discurso es a la vez controlada, seleccionada, organizada y redistribuida por un cierto número de procedimientos que tienen por función de conjurar los poderes y los peligros, de dominar el evento aleatorio, de esquivar la pesada, la temida materialidad." (Foucault, 1971: 10-11).

En efecto, el sujeto hablante, en su relación con el discurso que pronuncia, se da cuenta que no es él el que habla. Podemos afirmar con certeza que el sujeto que habla en realidad es hablado. Pero, ¿acaso nos encontramos en una aporía que imposibilita al sujeto asumir la responsabilidad de su discurso? Veamos este problema en el siguiente apartado.

\section{EL ANÁLISIS DEL DISCURSO Y EL PROBLEMA DEL SUJETO}

No cabe duda que la obra de Foucault es útil para la reflexión de la íntima relación entre discurso, poder y saber. Si pensamos en la vinculación poder y saber, nos encontramos con el sujeto necesariamente. Pensemos el caso de si fuéramos atenienses de la época de Aristóteles. Es seguro afirmar que nuestras discursividades corresponderían a las que fueron posibles en ese periodo. En tanto prácticas de lenguaje, las discursividades están determinadas por nuestras relaciones de poder, las mismas que determinan la forma de ver el mundo. Somos hijos de nuestro tiempo. Esta condición es inevitable. Es en este sentido, Foucault habla del sujeto como resultado político e histórico, lejos de ser substancia libre sin condicionante alguno.

Sin embargo, lo anterior no significa que no haya sujeto en el pensamiento de Foucault. Lo hay evidentemente en forma flagrante. ¿Cómo esperar que alguien que proyecta "la muerte del hombre" 3 no proyecte en su obra una idea del sujeto?:

"Hace tres siglos, había quienes se sorprendían porque Espinoza quería la liberación del hombre, aunque él mismo no creía en esta libertad ni en su existencia específica. Hoy, nuevamente hay quienes, como si se tratara de reencarnados de aquellos sorprendidos, se extrañan porque Foucault participana en las luchas políticas, él que se había referido a la muerte del hombre" (Deleuze, 1986: 96).

Esta cita nos sugiere incluso que veamos en la vida misma de Foucault el sujeto en acción, testimonio de un saber y un poder.

En efecto, Michel Foucault, al correlacionar la vida, el trabajo y el lenguaje como características inmanentes del hombre, nos está diciendo que el sujeto se mueve necesariamente por relaciones de poder ${ }^{4}$. Es justamente en los diferentes planos de la actividad social, política y cultural que las subjetividades sociales, los juegos de verdad, las prácticas de todo orden, las epistemes construyen lo que llamamos el hombre ${ }^{5}$. Lo que está en juego aquí con las "ciencias humanas no es el de constituir el hombre sino de disolverlo" (LéviStrauss, 1966: 326). En otras palabras, la construcción del sujeto no está en una finalidad última, sino en la que han dictado los discursos, entre los que están evidentemente los científicos, religiosos, políticos, económicos. La importancia capital de los discursos está entonces en la posibilidad de poder y de saber que trascienda las condiciones que hacen posible su emergencia como práctica. Ahora se trata de que los discursos dejen de construir al hombre o, mejor dicho que los hombres construyan otros discursos:

“Era necesario entonces que fueran [la etnología y el psicoanálisis]

${ }^{3}$ (Foucault, 1966: 353)

${ }^{4}$ No vamos a discutir la controversia de Jürgen Habermas contra la importancia que le otorga Foucault al concepto de poder (Habermas, 1989). Esta revisión merece una reflexión aparte.

${ }^{5}$ No está de más recordar que en Foucault se trata del hombre como objeto filosófico, no el hombre del "humanismo clásico", sino del hombre en su finitud que las ciencias modernas niegan en su búsqueda de positividades. De aquil su contundente afínacir 
totalmente dos de las ciencias del inconsciente: no porque alcancen en el hombre lo que está debajo de su consciencia, sino porque se dirigen hacia lo que, fuera del hombre, permiten que sepamos, por un saber positivo, lo que (Foucault, 1966: 390).

En este proceso, un saber positivo que sólo auto-genere sus condiciones de emergencia en la vida, la economía y el lenguaje, será incapaz de trascender la coacción que sus propios discursos producen. De manera que la relación poder y saber es inexorable.

Dicho lo anterior, conviene preguntarse: ¿cómo es posible construirse (el sujeto) a través de las relaciones de poder? Apoyémonos, para responder a esta pregunta, en Paul Patton:

“Porque hay un 'sujeto' que sólo existe bajo formas muy diferentes, porque los poderes del ser humano pueden ejercerse en un numero infinito de formas, este sujeto no puede servir de fundamento a un juicio normativo en el sentido que lo entienden Fraser o Habermas, es decir a una norma que proporcionaría una respuesta única y universal a la cuestión: ¿por qué hay que resistir a la dominación?" "1992: 92).

Ahora bien, si tomamos en cuenta que el poder en Foucault es un rapport de forces entre sujetos, se nos revela inmediatamente la lógica que el sujeto participa (como un acto de consentimiento) o resiste a la dominación (como un acto de transformación). En esto consiste el dictado de la discursividad que domina al sujeto.

Con lo anterior, resulta interesante observar que el tratamiento que Foucault da a la idea de sujeto es tan fina (difícil de aprehender, diríamos) que permite reconocer entonces la posibilidad de los sujetos de hacer frente al poder, pero también a los placeres que este le concede. Por esto, Foucault habla del

"principio de una crítica y de una creación permanente de nosotros mismos en nuestra autonomía: es decir un principio que está en el corazón de la consciencia histórica que la Aufklärung tuvo de ella misma. Desde este punto de vista, yo vería, sobre todo, una tensión entre la Aufklärungy el humanismo más que una identidad" (Foucault, 2009).

Así, en el ensayo "Qu'est ce que les Lumières ?" de Foucault (/bidem), nos podemos dar cuenta de la importancia del sujeto mismo para su autogeneración, en el corazón de sus relaciones de poder. Como bien lo señala
Patton:

"no es que el ejercicio de un poder sobre los otros sea siempre negativo, ni "no haya siempre que evitar un estado de dominación, sino sobre todo que la existencia de una resistencia generalizada en formas de poder individualizante demuestre la necesidad de una nueva economía de relaciones de poder 7 "1 $(1992,96)$.

¿Cómo no insistir en la presencia de ver un sujeto en la filosofía de Michel Foucault? Precisamente, nuestro autor no deja de indicarnos que la subjetividad que se establece entre los sujetos promueve una serie de relaciones poder, los cuales no son otra cosa que la consecuencia de los momentos históricos que están cruzados por acciones y éstas a su vez por lo que pensamos, sentimos, deseamos. En definitiva, y en congruencia con todos los temas que se constatan en Foucault, se establece que sobre el eje del saber, del poder, pero también del de la ética, podemos respondernos:

"cómo nos hemos constituido como sujetos de saber; cómo nos hemos constituido como sujetos que ejercemos o sufrimos las relaciones de poder cómo nos hemos constituido como sujetos morales de nuestras acciones." (Foucault, 2009).

¿Cómo no intentar una mirada que pueda responder a la arqueología de nuestras ciencias contemporáneas (discontinuidades discursivas); pero también cómo no interesarse de sus impactos sobre nuestras relaciones de poder y de saber entre los sujetos?

\section{HACIA UNA DEFINICIÓN DEL ANÁLISIS DEL DISCURSO}

Una vez que hemos repasado coordenadas del pensamiento de Foucault para el objeto de reflexión que aquí nos ocupa, en los siguientes apartados expondremos algunas consideraciones que apuntan a una utilidad teóricametodológica para el analista. Comencemos por discutir una posible definición de análisis del discurso.

No nos interesa ofrecer una definición formal del vocablo análisis del discurso, ya que consideramos que nos encontramos en pleno desarrollo de

7 Ponemos en cursivas la afirmación de Foucault, citada en Patton (1992). 
la disciplina. En efecto, el análisis del discurso representa ya una disciplina a justo título, por el hecho de haberse convertido en una práctica de la discursividad. Además de Michel Foucault quien, como ya dijimos, funda las bases de esta disciplina, podemos aludir a Michel Pêcheux (1969), quien es autor de los primeros análisis sobre corpus concretos, tratando de rastrear sus trayectorias discursivas, a partir de micro-análisis sistemáticos. Patrick Charaudeau $(1983,2005)$ y Dominique Maingueneau $(1984,1980)$, cada uno por su parte proponen analizar el discurso valiéndose de otras disciplinas como la semiótica, la lingüística y la semántica; muchas de sus aportaciones se fundan en la consideración de las características de los géneros, con lo cual se logra una pertinencia metodológica en el análisis. De Ambos autores hay una diversidad de trabajos que ya son referencia como el Dictionnaire d'analyse du discours (Charaudeau y Maingueneau, 2002). El holandés Teun A. Van Dijk se ha preocupado por la relación del discurso con la ideología, en un contexto cognitivo $(1996,2009)$. Todos estos autores tienen algo en común: su aproximación es crítica y sus marcos teóricos tienen su origen, de una manera u otra, en la fundación foucauldiana del discurso.

Siguiendo de igual manera esta línea, interesa decir que el análisis del discurso, al encontrarse en pleno desarrollo, sobre todo su dimensión metodológica merece ser profundizada. Epistemológica y teóricamente, podemos considerar, el análisis del discurso posee ya sus bases, no así en el plano metodológico. Por esto es sumamente comprensible que esta disciplina continúe conviviendo con otras disciplinas, en lo que conocemos como la interdisciplinariedad. Esta interdisciplinariedad no sólo convoca a las ciencias del lenguaje. Tratándose del análisis del discurso, según Maingueneau, esta disciplina "es un entrecruce de las ciencias humanas: psicoanálisis, antropología, sociología, historia, psicología social o cognitiva" (1998). Cierto, sin embargo, desde la perspectiva de cada disciplina puede decirse lo mismo. Lo importante en esta afirmación es que nos inspira a identificar la tarea que le corresponde al análisis del discurso en el proceso de generación del conocimiento. Para llegar a este objetivo, proponemos pensar lo que sería su objeto empírico. Consideramos que este objeto es el texto del discurso.

\section{EL TEXTO DEL DISCURSOCOMO OBJETO EMPÍRICO}

Para el trabajo metodológico en el análisis del discurso es importante identificar su objeto empírico. Éste es el texto del discurso. Este concepto resulta de mucho interés, cuando nos damos cuenta que comprende infinidad de referentes empíricos tales como un programa de televisión o de radio, un reportaje de prensa, pero también textos de la vida cotidiana: una plática de café, una clase universitaria, un saludo de pasillo. Efectivamente, los ejemplos de la vida cotidiana atrás son textos, en toda justa precisión, cierto son efímeros, y su aprehensión para ser analizados podrían salvarse al poder ser memorizados (registrados) en algún dispositivo tecnológico. Por otro lado, todo documento histórico o formal, por supuesto, también pertenece a la categoría de texto ${ }^{8}$. En este sentido, la idea de texto subsume el concepto de género, éste último refiriéndose a la parte abstracta del texto 9 .

Dicho lo anterior, el concepto de texto, al correlacionarlo, en su dimensión discursiva, lo definimos ${ }^{10}$ como una unidad de signos (homogéneos 0 heterogéneos), ordenados sintáctica y paradigmáticamente, que tienen la finalidad de contener discursos y producir acciones. Así, un texto se presenta como un complejo tramado (tela) de signos en sistemas de lenguaje: lengua, corporalidad, sonoridad y/o visualidad (lo audiovisual, por ejemplo). Como vemos, el texto es la parte material que contiene los signos de los sistemas de lenguaje, por los cuales se produce lo que a la postre son los discursos (dimensión abstracta). Un texto es en consecuencia producto de un conjunto de operaciones sígnicas, sin las cuales no sería posible la presencia de los discursos y mucho menos de las acciones.

En este punto, podemos ya apreciar que metodológicamente, antes de pasar a un análisis del discurso, hemos de conocer la "mecánica" del texto que implica un análisis textual"1. Este tipo de análisis recorre las dimensiones formales de los géneros, sobre las cuales la lingüística es un auxiliar valioso, hasta encontrar planos semióticos, cuya formalidad se encuentra en sintagmas y paradigmas de los signos que componen al texto. No se trata de una descripción puramente morfológica de las unidades analíticas, sino de ir estableciendo "capas" de

${ }^{8}$ Conviene recordar que el sentido etimológico de texto comprende el sentido de tela, trama: $\mathrm{http} / / / \mathrm{www}$. cnrtl.fr/etymologie/texte

"Distinguimos entonces "género" de "texto" del discurso: el primero es una categoría que analiza la constitución, producción y consumo de los textos, en su dimensión abstracta; mientras que el segundo se sumerge en la textualidad, en la materialidad que representan los significan-

${ }^{10}$ Inspirados en la obra de Yuri Lotman (1970).

${ }^{11}$ La obra de Jean-Michel Adam demuestra el potencial de establecer puentes excelentes entre la textualdad y el análisis del discurso (2005). 
sentido por la lengua. Es evidente la necesidad de recurrir a diferentes disciplinas como la semiótica, el análisis textual, e incluso la retórica, para encontrarse con el análisis del discurso. En medio de esta interdisciplinariedad se convocan diversos conceptos (signo binario, signo triádico, texto, textualidad, discurso, lenguaje), que en estos momentos se encuentran desarrollados y de los cuales, el analista echa mano, según sus proyectos analíticos.

Con base en los elementos anteriores, podemos entonces establecer que el texto es la materialización de la expresión primera del lenguaje y enseguida del discurso. Compuesto por elementos textuales (sistémicos) y extra-textuales (extra-sistémicos), el texto posee códigos que detonan su lectura (Lotman, 1970). Estos códigos es ya el objeto de investigación del análisis del discurso. En esta misma perspectiva, el abordaje analítico, todavía entre la textualidad ${ }^{12}$ y el sentido, a través de los enunciados, nos va revelando la función cultural del texto del discurso que transmite un significado completo. En otros términos, un texto es un conjunto de signos, organizados de manera que producen un discurso.

Visto este proceso metodológico, queda claro que es necesario aproximarse primero, a "la textualidad del texto", para luego pasar a nivel del discurso. Un análisis puramente lingüístico o semiótico no es suficiente para identificar la discursividad de los textos. El análisis del discurso da paso al umbral abstracto e ideológico de las prácticas discursivas ${ }^{13}$.

\section{UNA DEFINICIÓN DE ANÁLISIS DEL DISCURSO}

Michel Foucault no define formalmente el análisis del discurso. Pero el tratamiento del vocablo que desarrolla en sus obras se encuentra, como decíamos, como un método, al pivotear el telón epistemológico, teórico y metodológico:

"he puesto sobre el telar toda una serie de nociones (formaciones discursivas, positividad, archivo), he definido un dominio (los enunciados, el
campo enunciativo, las prácticas discursivas), he tratado de hacer surgir la

${ }^{12}$ La textualidad sería entonces las cualidades de los signos en lenguaje, así como sus posibles combinacio12 La textualidad seria entonces las cualidades des
nes que se necesitan para concretizar un texto.

${ }^{13}$ Conviene anotar que el concepto de "ideología" aquí referido significa conjunto de creencias e ideas que en discurso buscan la conservación de la iden
utopía. Seguimos el trabajo de Ricœur (1997). especificidad de un método que no fuese ni formalizador ni interpretativo ${ }^{14}$; en suma, he apelado a todo un aparato, cuyo peso y, sin duda, la maquinaria extraña son engorrosos" (1990: 227).

Sin duda, ha correspondido a los analistas el tratar de desarrollar y fortalecer los principios de Foucault. De igual manera, y en función de las necesidades de cada disciplina, desde la cual se trabaja el análisis del discurso, se ha tenido que inventar (en el sentido heurístico), diversas metodologías que resuelvan las preguntas de investigación.

El autor de L'ordre du discours está consciente de su propuesta, la cual, como él mismo afirma que su método no ha de ser "ni formalizador ni interpretativo". Esto significa que la tarea metodológica queda en manos del analista, a condición de no proceder a interpretar ${ }^{15}$ su objeto de estudio. ¿Pero qué es discurso entonces? Abordemos lo que Foucault entiende por formación discursiva, concepto que más se acerca a la noción de discurso en Foucault:

"[La formación discursiva] es el principio de dispersión y de repartición, no de las formulaciones, no de las frases, no de las proposiciones, sino de los enunciados (en el sentido que he dado a esta palabra), el termino de discurso puede ser establecido: conjunto de enunciados que dependen de un mismo sistema de formación, y así podré hablar de discurso clínico, del discurso económico, del discurso de la historia natural, del discurso psiquiátrico" (Foucault, 1990: 181).

Esta definición de formación discursiva permite ver claramente cómo el análisis de discurso identifica, por las referencias temáticas más generales, la pertenencia genealógica de los discursos. Así, podemos establecer el siguiente esquema jerárquico de los discursos:

\section{Discursos}

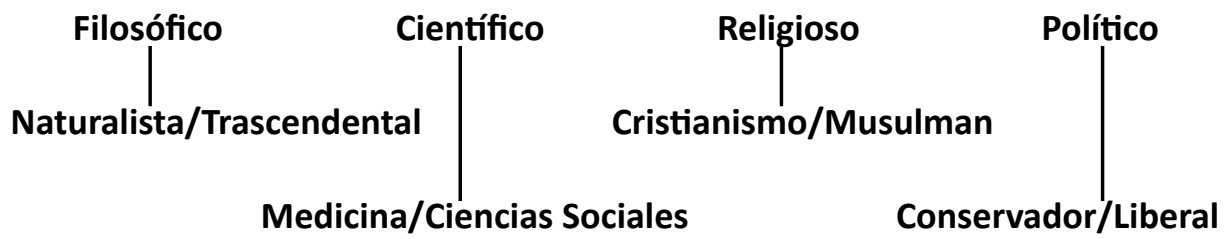

${ }^{14}$ Nosotros subrayamos.

${ }^{15}$ Sobre la dimensión interpretativa, referiremos en la parte final de este trabajo. 
Este esquema y los ejemplos pueden considerarse arbitrarios, la intención es simplemente ilustrar cómo cualquier discurso pertenece a una "genealogía", al menos por su temática. La propuesta de Foucault demanda trazar "genealogías" finas, en el tiempo y espacio histórico. Por otro lado, este esquema permite pensar posibles influencias, entre los discursos, de forma horizontal y esto en razón de la emergencia de discursos, proponiendo nuevas o rehabilitadas epistemes. De lo abstracto que es en sí el discurso, su análisis comienza sobre el plano de la lengua: la tarea del analista es entonces la de identificar los enunciados y su pertenencia a algún régimen discursivo. Tal manera de ver el objeto del análisis del discurso está en concordancia con la consideración de la idea de "texto" (dimensión empírica del discurso), que hemos desarrollado líneas arriba.

Una vez revisado lo anterior, estamos en condiciones de proponer una definición del análisis del discurso, que no pretende ser definitiva, sino sólo una referencia íntimamente asociada a sus posibilidades metodológicas: es un método que analiza toda producción del lenguaje, particularmente el verbal (sin dejar de lado el audio-visual que posee también discursividad), con el fin de identificar componentes ideológico-políticos, retórico-afectivos, en todo acto de comunicación y de información. Al mismo tiempo relaciona dichos componentes en uno o varios regímenes discursivos, tanto en la continuidad y discontinuidad de la historia.

\section{ACOTACIONES METODOLÓGICAS EN EL ANÁLISIS DEL DISCURSO}

Primeramente es importante recordar que el análisis del discurso no es el análisis de contenido. Este último, como sabemos, se centra en la pura identificación temática y recurrente de ciertos componentes textuales, con base en categorías de análisis construidas en función del interés del investigador/institución. A decir de sus fundadores, la utilidad de este análisis sería entonces constatar "objetivamente" lo que está contenido en un texto. Así Bernard Berelson dice que "es una técnica (sic) ${ }^{16}$ de investigación para la descripción objetiva, sistemática y cuantitativa del contenido manifiesto de las comunicaciones, teniendo como objetivo interpretarlas ${ }^{17 \prime \prime}$ (citado en

${ }^{16}$ Notemos que Berelson concibe al análisis de contenido como una técnica, lo que ya nos indica una preocupación de orden operatorio, antes que asumir una actitud arqueológica, a la manera de Foucault.

${ }^{17}$ Nosotros subrayamos.
Krippendorff, 1990: 29). O bien en palabras del mismo Krippendorff: "es una técnica (sic) de investigación destinada a formular, a partir de ciertos datos, inferencias reproducibles y válidas que pueden aplicarse a su contexto" (1990:

28). Estos presupuestos epistemológicos del análisis de contenido se explican en el contexto del desarrollo de una sociología funcionalista y empirista. Su perspectiva "objetiva" supone una realidad que está ahí y que sólo habría abstraerla con datos (categorías verificables). El investigador sólo tiene que diseñar matrices para la captura de datos; pero incluso a veces casi nada porque ya se cuenta con programas informáticos, sobre los cuales recurren sus analistas.

Sin embargo, habría que reconocer que el análisis de contenido es una herramienta que ayuda a aproximarse, de manera exploratoria, a corpus cuantitativos de gran envergadura. Pero tal aporte queda únicamente en la constatación que presuponen las categorías, previamente establecidas por la investigación. Por contraste, el análisis del discurso, recorre las trayectorias genealógicas (identificación histórica de la emergencia de los discursos) y arqueológicas (las reglas de exclusión y validación de los enunciados de los discursos). En resumen, el análisis de contenido podría ser un paso metodológico de aproximación al análisis del discurso; no sustituye a este último, al menos que la pretensión de la investigación no sea el de tratar de comprender la relación de poder y saber que generan los discursos. El análisis de contenido puede ser útil al combinarse con otros métodos (un uso del estructuralismo metodológico, la semiótica, la estadística), a condición de sopesar su validez. Pero insistimos, el análisis de contenido no es el análisis del discurso ${ }^{18}$.

\section{EL ANÁLISIS DEL DISCURSO: UN OBJETO DE LENGUAJE}

La analítica del discurso interpela por definición al objeto lenguaje. Cuando se invoca el término discurso se implican conceptos tales como: texto, habla, lengua, lenguaje, enunciación, sujeto enunciador/sujeto locutor ${ }^{19}$, contexto. Conceptos que conviene saber integrar al análisis del discurso. Estos conceptos, viniendo de diferentes disciplinas, ponen en evidencia la

${ }^{18}$ La insistencia es por el simple hecho de que suele confundirse incluso entre ciertos investigadores. ${ }^{19}$ La diferencia de Oswald Ducrot (1995) entre el enunciador (responsable original del enunciado) y locutor (simple enunciador-reproductor de enunciados que no le deben ser atribuidos, bajo una "responsabilidad 
convivencia interdisciplinaria que caracteriza a la retórica, a la lingüística, al análisis conversacional, a la socio-lingüística, al análisis textual, a la semiótica, al análisis de contenido, a la teoría de la argumentación; y en otros planos interdisciplinarios con el resto de las ciencias sociales, particularmente con la hermenéutica y la filosofía del lenguaje. Es en medio de estas disciplinas que el análisis del discurso, en algún momento, tiene que echar mano para el buen desarrollo de sus resultados analíticos.

En el análisis del discurso, entonces, las unidades de análisis bien pueden derivar del auxilio de otras disciplinas, por ejemplo proceder observando secuencias textuales, funcionales, comunicacionales; para más tarde pasar a unidades de interpretación basadas, por ejemplo, en metáforas, en la dispersión discursiva del discurso reportado, en la circulación lexical (proceso de identificación lingüístico que merece interpretación asociadas a regímenes (o formaciones) discursivos). No se trata por lo tanto de sólo identificar las configuraciones del texto del discurso: temáticas, roles de los sujetos enunciantes, las regularidades de composición (textuales: lingüísticas, visuales, sonoras, táctiles, de estilo), sino de llegar a la finalidad socio-política del discurso, como práctica social en una sociedad concreta, en el espacio y el tiempo; es decir los planos arqueológicos y genealógicos foucauldianos.

\section{PROYECTO CIENTÍFICO Y SOCIAL DEL ANÁLISIS DEL DISCURSO}

Para Dominique Maingueneau

"El interés que gobierna al análisis del discurso es el de aprehender el discurso como intrincación de un texto y de un lugar socia/ ${ }^{20}$, es decir que su objeto no es ni la organización textual ni la situación de comunicación, sino lo que les convoca a través de un dispositivo de enunciación específico. Este dispositivo deriva a la vez de lo verbal y de lo institucional: pensar los lugares independientemente de los discursos que autorizan, o pensar los discursos independientemente de los lugares de donde se inscriben, sería quedar afuera de las exigencias que fundan el análisis del discurso." (2005: 66).

Anotación de suma importancia que subraya la grande diferencia con otras aproximaciones como el del análisis de contenido. El "Iugar social" no es otra cosa que la respuesta que presupone el análisis: ¿quién habla y desde

${ }^{20}$ Nosotros subrayamos. dónde? Con esto, el analista puede rastrear la genealogía de toda producción discursiva. Por esto, el objeto de análisis es transfrástico, transtextual; es decir que no se remite solamente al estudio de la frase (en la dimensión textual del objeto empírico, que sería objeto de la lingüística), sino que busca el sentido que "ésta fuera del texto", es decir en los discursos que envuelven la acción comunicativa de la sociedad.

Es la descripción pura de los acontecimientos discursivos (Foucault, 1990: 43) que interesa al análisis del discurso como

"[conjunto] de reglas que permiten construir eventualmente otros enunciados aparte de ésos [...] La descripción de los acontecimientos del discurso plantea otra cuestión muy distinta: ¿cómo es que ha aparecido tal enunciado y ningún otro en su lugar?" (Foucault, 1990: 43- 44).

Desde la arqueología foucauldiana es la de tratar de encontrar las reglas de exclusión del discurso. Hasta aquí, hemos podido ver que el objetivo social y científico del análisis del discurso se centra en la identificación del poder de acción de los discursos, con lo cuales todo sujeto (individuo o institución) hace posible su enunciación. A la manera de un Bakthine:

"en la vida cotidiana, nos referimos sobre todo a lo que dicen los otros: nos remitimos, evocamos, analizamos, discutimos los discursos, las opiniones, afirmaciones, informaciones, nos indignamos, estamos de acuerdo, rechazamos, a los discursos nos referimos" (Bakthine, 1978: 157).

Efectivamente, y aunque nuestro autor ruso se encuentra en otra perspectiva, este referir a lo que dicen "los otros" no es otra cosa que la inscripción discursiva del sujeto enunciante subsumido en otros discursos. llustremos lo anterior con el caso del vocablo "La reforma de los energéticos en México". En todo momento, este enunciado (si el sujeto enunciante está a favor de dicha reforma) trabaja por y para la globalización (discurso político) y sus respectivas acciones (positividades en el plano de concretizaciones materiales). Este mismo enunciado puede encontrarse comentado, reproducido, en los medios masivos de comunicación, con lo cual no es ya el sujeto hablante el responsable de su expresión, sino el discurso que en un momento histórico emerge y es validado por otras instancias (en este caso particularmente de orden político y económico).

De modo que todo discurso se asocia a una actividad humana (administrativa, publicitaria, médica, industrial, política), en la forma genérica (géneros de discurso: noticiario televisivo, telenovela, novela, folleto turístico, reportes, 
informes, formularios, etc.). Corresponde entonces al análisis del discurso establecer quién habla, no qué sujeto con nombre y apellido, sino qué discurso y qué reglas de exclusión se encuentran en su funcionamiento. De esta manera, el análisis del discurso es capaz de aproximarse no sólo a la constitución de los discursos, sino del sujeto enunciante en su subjetividad social.

Con lo anterior, podemos decir que el proyecto social del análisis del discurso permite

"revisar esas síntesis fabricadas, esos agrupamientos que se admiten de ordinario antes de todo examen, esos vínculos cuya validez se reconoce al entrar en el juego. Es preciso desalojar esas formas y esas fuerzas oscuras por las que se tienen costumbre de ligar entre sí los discursos de los hombres. Y más que dejarlas valer espontáneamente, aceptar el no tener que ver, por un cuidado de método y en primera instancia, sino con una población de acontecimientos dispersos." (Foucault, 1990: 34-35).

En otras palabras, el análisis del discurso es capaz de develar lo que está oculto por un movimiento arqueológico y genealógico sobre el discurso. Pero, ¿es suficiente este proceder del análisis del discurso (como método) en el ámbito de las ciencias humanas?

\section{CONCLUSIONES}

Al cabo de todo el anterior recorrido, podemos establecer que el análisis del discurso foucauldiano no es un método que se pretendería puramente científico. Su aproximación analítica es sumamente cuidadosa al no dejar afuera la importancia del poder, con el cual es posible la misma generación del conocimiento. En este sentido, el análisis del discurso trabaja como un metadiscurso del propio conocimiento que produce. En este contexto, toma al pie de la letra que

"todo enunciado se encuentra en un encadenamiento de enunciados organizados, en relación a un sistema de plazas enunciativas y de varios sistemas retoricos de disposición [...] Plazas enunciativas y disposiciones no son invenciones que se renueven incesantemente por un sujeto de enunciación, (Pêrcheux et.al., 1982: 120)
Pero, ¿̇es posible concebir una neutralidad axiológica del discurso del propio método del análisis del discurso? Siendo fieles a la perspectiva de Foucault, no habría discurso inocuo, incluyendo el discurso científico del análisis del discurso. Sobre el plano de la cientificidad de este método, una aporía se presenta: ¿̇lo que deriva el análisis del discurso no porta la huella de otro discurso? Creemos que sí. Si bien, el análisis del discurso, en calidad de método, nos devela la arqueología y genealogía de los discursos, ¿ cómo salvar la neutralidad axiológica que podría presuponerse? Por esto, la propuesta ricœuriana (1986) nos invita a pensar que el análisis del discurso necesita una postura hermenéutica.

Efectivamente, un "distanciamiento alienante" y un "distanciamiento de pertenencia" (Ricœur, 1986: 113-114), deben aquilatarse por el analista. De aquí que postulemos la integración de la perspectiva hermenéutica al análisis del discurso. Contra Foucault, una hermenéutica se presenta inevitable por el hecho de reconocer que postular objetividades en los textos no es otra cosa que presuponer una sistematicidad de análisis como garantía de cientificidad; pero también es necesario reconocer que no abandonar la distancia afectiva (para asumir una actitud crítica de la representación contenida en el texto, cuando el sujeto analizante pertenece a la comunidad histórica que es objeto de estudio), conlleva a una reproducción del sistema. Entre estos dos distanciamientos se encuentra la parte hermenéutica de todo análisis. Dicho lo anterior, se trataría de superar estos dos distanciamientos por un trabajo interpretativo, donde el propio analista es el centro de su propia producción discursiva, la cual podría hacer más productivo los resultados de sus investigaciones. Esto en razón de que

"De igual forma que la lengua, actualizándose en el discurso, se sobrepasa como sistema y se realiza como acontecimiento, de igual forma, entrando en el proceso de la comprension, el discurso se sobrepasa, como acontecimiento en la significación" (Ricœur, 1986: 117).

En efecto y en el fondo, consideramos que no hay oposición entre una hermenéutica y una aproximación foucauldiana del análisis del discurso, ya que justamente de lo que se trata es de transformar nuestros discursos por los discursos mismos. Ya sea estableciendo arqueologías y genealogías (en plural), o bien dándole la razón al otro (Gadamer, 2007), los discursos no deja de estar presentes en nuestras vidas. $Y$ es aquí entonces donde está la responsabilidad de las ciencias sociales y de cada analista que pretenda, en su tarea científica, 
postular otras formas de percibir la realidad social, inexorablemente sobre un plano del poder, a propósito del cual Foucault no deja de tener razón. Al final, el análisis del discurso tiene que conservar su misión: hacer del lenguaje un objeto científico, sin negar su dimensión política.

\section{REFERENCIAS}

ADAM, Jean-Michel (2005), La linguistique textuelle. Introduction à l'analyse textuelle des discours. Paris: Armand Colin.

BAKHTINE, Mikhaïl (1978), Esthétique et théorie du roman. Paris: Gallimard. CHARAUDEAU, Patrick y MAINGUENEAU, Dominique (2002), Dictionnaire d'analyse du discours. Paris: Seuil.

CHARAUDEAU, Patrick (2005), Langage et discours. Éléments de semiolinguistique. Paris: Hachette.

CHARAUDEAU, Patrick (2005), Les médias et l'information. L'impossible transparence du discours. Bruxelles: Institute national de l'audiovisuel.

DELEUZE, Gilles (1986), Foucault. Paris: Minuit.

DUCROT, Oswald (1995), L'argumentation dans la langue. Paris: Mardaga.

FOUCAULT, Michel (1966), Les mots et les choses. Une archéologie des sciences humaines. Paris: Gallimard.

FOUCAUL, Michel (1990), La arqueología de/ saber. México: Siglo XXI.

FOUCAULT, Michel (1971), L'ordre du discours. Paris: Gallimard.

FOUCAULT, Michel (1994), Dits et écrits. Vol II. Paris: Gallimard.

FOUCAULT, Michel (2009), “Qu'est-ce que les Lumières ?”, en http://foucault.
info/documents/whatlsEnlightenment/foucault.questcequeLesLumieres. fr.html

GADAMER, Hans-Georg (2007), Verdad y Método /, Salamanca: Sígueme.

HABERMAS, Jürgen (1989), El discurso filosófico de la modernidad. Madrid: Taurus.

KRIPPENDORFF, Klaus (1990), Metodología de análisis de contenido. Barcelona: Paidós.

LÉVI-STRAUSS, Claude (1962), La pensée sauvage. Paris: Plon.

LOTMAN, Yuri (1970), "El concepto de texto", en Estructura del texto artístico. Madrid: Istmo.

MAINGUENEAU, Dominique (1984), Genèse du discours. Bruxelles: Mardaga.

MAINGUENEAU, Dominique (1980), Introducción a los métodos de análisis del discurso: problemas y perspectiva. Paris: Hachette.

MAINGUENEAU, Dominique (1998), "Les tendances françaises e analyse du discours". En línea: http://www.lang.osaka-u.ac.jp/ benoit/fle/conferences/ maingueneau.html

MAINGUENEAU, Dominique (2005), "L'analyse du discours et ses frontières",

en Marges linguistiques. Revue Eléctronique en Sciences du Langage, No

9. Saint-Chamas: M.L.M.S. Éditeur. En línea: http://www.revue-texto.net/ Parutions/Marges/00_ml092005.pdf

PATTON, Paul (1992), "Le sujet de pouvoir chez Foucault", en revista Sociologie et sociétés, Vol. 24, No 1, 91-102 pp. Montréal: Les Presses Universitaires de Montréal.

PÊCHEUX, Michel (1969), Analyse automatique du discours. Paris: Dunod.

PÊCHEUX, Michel et.al. (1982), "Présentation de l'analyse automatique du discours (AAD69): théories, procédures, résultats, perspectives", en revista Mots, No 4. 95-123 pp. Lyon: École Normale Supérieur de Lyon. En Línea: http:// www.persee.fr/web/revues/home/prescript/article/mots_0243-6450_1982_ num_4_1_1053

RICCEUR, Paul (1986), Du texte à l'action. Paris: Seuil.

RICCEUR, Paul (1997), L'idéologie et I'utopie. Paris: Seuil.

VAN DIJK, Teun (2009). Discurso y poder. Contribuciones a los estudios críticos del discurso. Barcelona: Gedisa.

VAN DIJK, Teun (1996), Estructuras y funciones del discurso. México: Siglo 


\section{CARLOS GONZÁLEZ-DomíngUEZ}

\section{cgdomin@hotmail.com}

Doctor en Ciencias de la Información y de la Comunicación por la Université de la Sorbonne Paris-III. Investigador de la Universidad Autónoma del Estado de México. Líneas de investigación: Análisis del discurso, Análisis Semiótico y Análisis Retórico de los Medios Masivos de Comunicación; Epistemología de las Ciencias de la Comunicación. Especialista en el Análisis del Ethos Comunicacional. Miembro del Sistema Nacional de Investigadores.

\section{Lenin Martell-Gámez}

leninmartell@yahoo.com

Profesor de la Universidad Autónoma del Estado de México. Es licenciado en Periodismo y comunicación colectiva por la UNAM, y ha realizado sus estudios de posgrado en la Universidad de Boston, Universidad Complutense de Madrid y en la Facultad de Ciencias Políticas de la UNAM. Desde el 2001,

Lenin Martell ha sido profesor en varias universidades del país. Ha sido también profesor invitado en programas de posgrado de la Universidad del Norte de Texas. Es coautor de los libros, Hacia la construcción de una ciencia de la comunicación en México; $A 25$ años del informe MacBride, y Políticas de comunicación y desarrollo regional en América Latina, y Agenda académica para una comunicación abierta. 